\title{
Influence of Antistripping Additives and Rejuvenators on Healing Performance of Moisture-Damaged HMA
}

\author{
Dae-Wook Park (D), ${ }^{1}$ Tam Minh Phan (D), ${ }^{1}$ and Yeong-Min Kim (iD) ${ }^{2}$ \\ ${ }^{1}$ Department of Civil Engineering, Kunsan National University, Gunsan 54150, Republic of Korea \\ ${ }^{2}$ Department of Civil Engineering, Kyung Hee University, Yongin, Gyeonggi, 17104, Republic of Korea
}

Correspondence should be addressed to Yeong-Min Kim; choozang@kict.re.kr

Received 18 February 2020; Revised 5 April 2020; Accepted 28 April 2020; Published 29 May 2020

Guest Editor: Zhen Leng

Copyright (C) 2020 Dae-Wook Park et al. This is an open access article distributed under the Creative Commons Attribution License, which permits unrestricted use, distribution, and reproduction in any medium, provided the original work is properly cited.

\begin{abstract}
This study aims to evaluate the effect of different rejuvenators and antistripping agents on the healing performance of hot mix asphalt (HMA). Two damage HMA series (e.g., moisture damage and aged damage) were subjected to either induction or microwave heating. A PG64-22 virgin and aged binder were used and modified with several additives. Three long-term aged binders (e.g., PAV5, PAV15, and PAV20) were conducted by pressure aging vessel (PAV) test. The moisture damage series fabricating with a new binder was further categorized into four different freeze-thaw (FT) cycles (e.g., 0FT, 1FT, 3FT, and 5FT). Also, the aged series was fabricated with three different aged binders. A total of eight damage-healing cycles were applied to all asphalt mixtures, examined by the three-point bending test. The moisture resistance of modified asphalt mixture was examined by indirect tensile strength test. Overall, asphalt mixtures modified with either antistripping additives or rejuvenators not only obtained higher moisture resistance but also gained better healing performance under moisture damage. In addition, the study showed a probable correlation between moisture damage and long-term aging in terms of healing performance, such as PAV15 and 3FT cycles and PAV20 and 5FT cycles.
\end{abstract}

\section{Introduction}

Moisture damage is one of the main factors affecting the durability of asphalt mixtures [1]. The application of freezing and thawing cycles is adopted to replicate in-service moisture damage on pavements. Moisture damage greatly affects internal structure and consequently results in pavement degradation. This occurs when moisture from either rainwater or snowmelt makes its way into existing microcracks during high temperature, after which, as the temperature drops below freezing point, the moisture within the microcracks begins to freeze and expand. The repetition of this occurrence leads to accelerate aging of asphalt binders [2]. The strength of interaction is reduced, which creates a weak asphalt-aggregate system [3]. However, moisture damage can be prevented either by improving the adhesion strength of asphalt aggregate or by preventing water intrusion on asphalt concrete [4]. Nowadays, antistripping agent is used to enhancing moisture resistance of asphalt mixture. This additive agent can improve internal structure of asphalt mixture, which enhances the adhesive of aggregate and binder [5]. In addition to reducing water intrusion, microcracks healing is also a promising solution [6]. Electromagnetic induction, microwave, and infrared have been used to heat asphalt concrete for healing purposes. It has been proved that the healing level of asphalt concrete can be improved by induction and microwave heating. During the heating process, mixture containing conductive additives is exposed to high frequency alternating magnetic fields. Based on the Joule law, the eddy current heats conductive particle. Then, the heat energy diffuses into the asphalt mixture to increase sample temperature [7]. A sufficient temperature leads to low viscosity of asphalt binder, and the binder can fill microcracks. This phenomenon is explained by the fact 
that asphalt binder is a temperature-dependent material. The first applied induction heating on the road has been taken on the A58 near Vlissingen in Netherland. After three years of paving time, the healing result was promising; this road could be heated in the expected time [8].

Aging is another factor influencing the performance of asphalt mixture, which occurs during production and construction and continues throughout the services life of asphalt pavements. Long-term aging caused asphalt binder to stiffen and embrittle, which leads to a high potential of cracking [9]. Repetition of the healing process may lead to similar aging attributes, which are easily recognized at late damage-healing cycles. According to SHRP, 20 hours aging in the PAV simulates the asphalt binder aging that occurs during 5-10 years of in-service HMA pavements [10]. Previous researches have been proved that rejuvenators could be used to restore some of the mechanical properties of an aged asphalt binder $[11,12]$. Wang et al. confirmed that sufficient rejuvenator could improve physical properties and crack resistance [13]. However, it was found that there was a lack of research focused on the performance of healed HMA under both moisture damage and aging effects. In reality, asphalt mixtures are subjected to aging and moisture damage simultaneously [14-16]. Hence, further investigation is also needed on the correlation between the long-term aging process and moisture damage.

This research aims to study the effect of different additive agents (e.g., antistripping agent and rejuvenator) on the healing performance of moisture damage asphalt mixture. Induction heating and microwave heating are used to heat asphalt mixture. Long-term aging is considered to find the correlation between moisture damage and aging in terms of healing performance. Two sample series are fabricated to archive the research objectives. First, the unaged asphalt binder is modified with four types of additive agents. These samples are going on to four different freeze-thaw (FT) cycles. Second series was fabricated with three levels of PAV asphalt binder (e.g., PAV5, PAV15, and PAV20). The healing performance of mixture is assumed by the threepoint bending (TPB) test, while the moisture resistance is conducted to indirect tensile strength (ITS) test. Steel wool fiber (SWF) is utilized to obtain a prime healing performance. All test samples are applied to eight damage-healing (DH) cycles. During healing process, the infrared camera (FlukeTiS20 model) is used to record the surface temperature of sample. The ANOVA and Tukey HSD post hoc are employed to find the correlation between moisture damage and aging in terms of healing performance.

\section{Materials and Methods}

2.1. Materials. Laboratory-fabricated HMA mixtures were used to conduct a series of experiments. Table 1 shows the gradation of experiment aggregate. The bitumen PG 64-22 had a penetration at $25^{\circ} \mathrm{C}$ of $70 \mathrm{~mm} / 10 \mathrm{~s}$ and a density of $1.02 \mathrm{~g} / \mathrm{cm}^{3}$. The $S W F$ has a diameter ranging from 70 to $130 \mu \mathrm{m}$, a density of $7.18 \mathrm{~g} / \mathrm{cm}^{3}$, a length of $4-4.5 \mathrm{~mm}$, and thermal conductivity of $80 \mathrm{~W} /$ $\mathrm{mK}$. The antistripping additives consist of silane additive,
Table 1: Aggregate gradation.

\begin{tabular}{lccc}
\hline Sieve size $(\mathrm{mm})$ & \multicolumn{3}{c}{ Aggregate } \\
& Coarse $(33 \%)$ & Fine $(60.5 \%)$ & Filler (6.5\%) \\
\hline 19 & 100 & 100 & 100 \\
12.5 & 83 & 100 & 100 \\
9.5 & 35.5 & 100 & 100 \\
4.75 & 1.7 & 79.3 & 100 \\
2.36 & & 41.3 & 100 \\
0.6 & & 16.5 & 100 \\
0.3 & & 10.5 & 100 \\
0.15 & & 6.2 & 56 \\
0.075 & & 4 & 47 \\
\hline
\end{tabular}

amine type surfactant, and stabilizer. Two kinds of antistripping additives named $\mathrm{A}$ and $\mathrm{B}$ have different proportions of silane additive to amine type surfactant. Rejuvenator types 1 and 2 had a viscosity of 79-90 and $60^{\circ} \mathrm{CSt}$ at $60^{\circ} \mathrm{C}$ and a density of 0.93 and $0.8 \mathrm{~g} / \mathrm{cm}^{3}$ at $20^{\circ} \mathrm{C}$, respectively. Further, three levels of long-term aged asphalt binder (e.g., 5 hours, 15 hours, and 20 hours) were used to fabricate aged mixtures.

2.2. Sample Preparation. The asphalt mixtures were prepared according to the Superpave Mix Design Method [17]. Two sample series were designed in this experiment (as shown in Figure 1). Table 2 shows the mix proportion of the moisture damage series. Four additives were used in this series, while only two additives were used in the aged series (Table 3). This is because of the weight limitation of binder from the PAV process. The SWF was utilized in both series to gain an optimum healing performance [18-20]. All test specimens were prepared according to the Superpave Mix Design Method [17], with an optimum asphalt binder content of $5.4 \%$ and target air void of $4 \pm 0.5 \%$.

Asphalt binder-additive mixing process involved preheating the asphalt binder for an hour at $160^{\circ} \mathrm{C}$. Once preheated, two percent of additive was then introduced and stirred thoroughly unto the binder. The mixture was allowed to sit in the oven for an additional hour (at $160^{\circ} \mathrm{C}$ ), stirring the mixture at 30 minutes interval. Based on ITS test requirements, a cylindrical test specimen had a dimension of $63.5 \mathrm{~mm}$ in height and $100 \mathrm{~mm}$ in diameter (Figure 2(a)). The TPB specimen which has a dimension of $100 \mathrm{~mm}$ in both height and diameter was followed. After curing for one day at room temperature $\left(25^{\circ} \mathrm{C}\right)$, the TPB molded specimen was cut into six equal semicircular samples with an overall size of $30 \mathrm{~mm}$ thick, $50 \mathrm{~mm}$ height, and $100 \mathrm{~mm}$ in width (Figure 2(b)). To ensure cracking of the sample at midpoint during the three-point bending test, a $10 \mathrm{~mm}$ depth and $2 \mathrm{~mm}$ thick notch were made at the base of the sample. This preexisting cut will ensure crack propagation at midsection. The notch dimension was based on the finding of García [21]. After cutting, these samples were let to dry at room temperature for 48 hours (to remove liquid due to cutting). Each mixture condition was prepared with three replicates to compute the average results. 


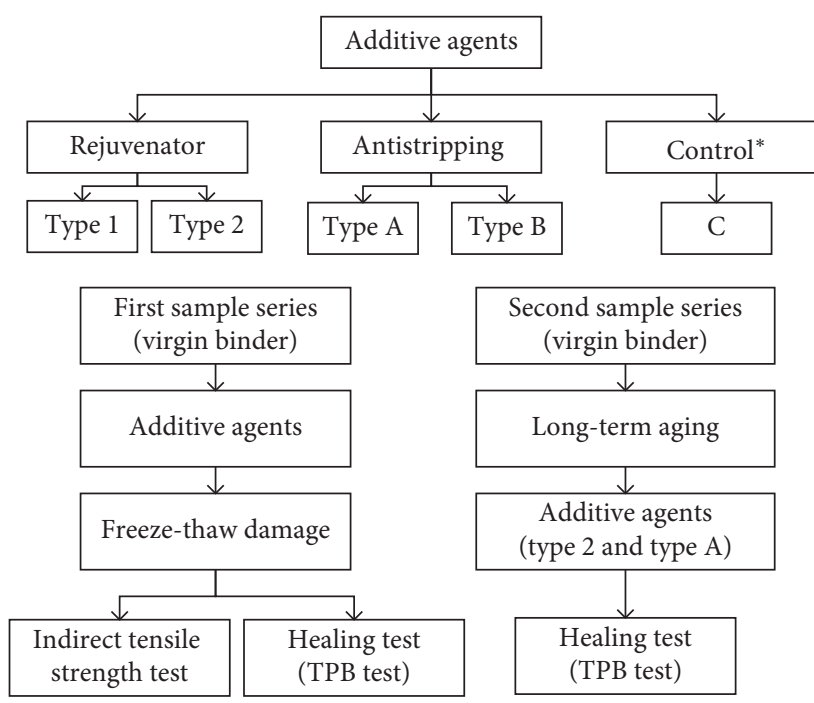

FIgURe 1: Research flowchart. * Mixture without additive agent.

TABLE 2: Mix proportion of moisture damage series.

\begin{tabular}{|c|c|c|c|c|c|c|c|}
\hline & \multirow{2}{*}{ New binder (by wt. of total mix) } & \multicolumn{5}{|c|}{ Additive agent (by wt. of binder) } & \multirow{2}{*}{ SWF (by wt. of binder } \\
\hline & & $\mathrm{C}$ & Type 1 & Type 2 & Type A & Type B & \\
\hline Induction heating & $5.4 \%$ & & & $2 \%$ & & & $6 \%$ \\
\hline Microwave heating & $5.4 \%$ & & & $2 \%$ & & & $2 \%$ \\
\hline
\end{tabular}

TABLe 3: Mix proportion of aged series.

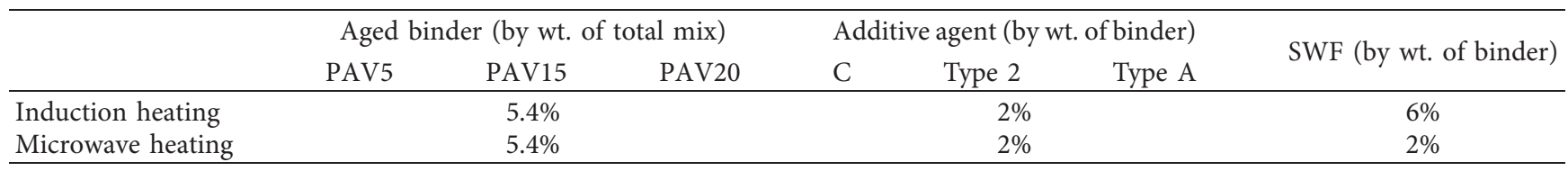

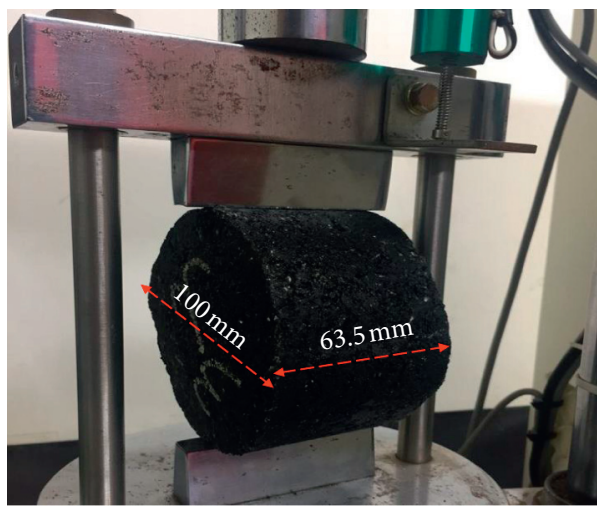

(a)

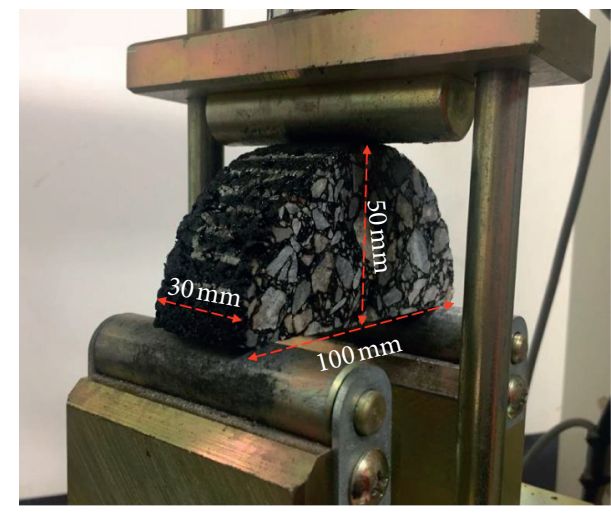

(b)

FIgure 2: Test setup for (a) ITS test and (b) TPB test.

\subsection{Test Methods}

2.3.1. Aged Binder Process. The asphalt binder underwent short-term and long-term aging. Short-term aging was simulated first, using RTFO (Rolling Thin-Film Oven) in accordance with D2872-12 [22], typically subduing binder for $85 \mathrm{~min}$ at $163^{\circ} \mathrm{C}$. The binder from the short-term aging process was further used for long-term aging simulation with the pressure aging vessel (PAV), which mimics the aging of road pavements during its life span. The PAV test 
was conducted with a pressure of $2070 \mathrm{kPa}$ on three different time periods: 5 hours, 15 hours, and 20 hours. Finally, specimens were fabricated using the long-term aged binder to investigate the effect of aging on healing performance.

2.3.2. Freeze-Thaw Process. The moisture damage series included 4 groups of freeze-thaw cycle: unconditioned/control (0FT), one cycle (1FT), three cycles (3FT), and five cycles (5FT). According to AASHTO T 283 [23], one freeze-thaw cycle includes saturating samples on a sealed vacuum container. Samples were supported by steel grills inside the container to acquire a minimum of $25 \mathrm{~mm}$ water above its surface. A relative vacuum of $13-67 \mathrm{kPa}$ was applied on the sealed container for 5-10 min. Once finished, the vacuum pressure was removed, and the samples were left submerged approximately $5-10 \mathrm{~min}$ more. Then, the saturated specimens were transferred unto sealed plastic bags filled with $10 \mathrm{ml}$ water and kept inside a freezer at $-18^{\circ} \mathrm{C}$ for 16 hours, after which, the specimens were placed unto a hot water bath at $60^{\circ} \mathrm{C}$; once the ice has melted, the sealed plastic was removed, and samples were left at this temperature for 24 hours. Finally, the specimens were then again transferred in a water bath at $25^{\circ} \mathrm{C}$ for 2 hours.

To investigate the effect of additive agents on moisture susceptibility, the indirect tensile strength test was conducted. The indirect tensile strength was recorded by applying a loading rate of $50 \mathrm{~mm} / \mathrm{min}$. The indirect tensile strength $S_{t}$ is calculated using

$$
S_{t}=\frac{2 P}{\pi D t}
$$

where $P$ is the maximum load $(\mathrm{kN}), t$ is thickness of specimen $(\mathrm{mm})$, and $D$ is the diameter of specimen $(\mathrm{mm})$.

2.3.3. Damage-Healing Process. To obtain brittle condition before TPB test, samples were placed in a refrigerator at aged binder process $-18^{\circ} \mathrm{C}$ for 2 hours. TPB test contained a loading roller at midpoint on the semicircular arch sample, supported by two fix rollers spaced at $80 \mathrm{~mm}$ apart (Figure 2(b)). A testing machine with a capacity of $100 \mathrm{kN}$ was used in this experiment. The test was performed under the loading rate of $0.9 \mathrm{~mm} / \mathrm{min}$ until failure, and the load was reduced $25 \%$ of the peak load. The test was carried out at room temperature (approximately $25^{\circ} \mathrm{C}$ ). After the TPB test, the damaged specimens were kept in ambient condition for 24 hours covered with paper a towel to ensure that the condensate moisture from freezing has totally dried.

Two healing treatments were used unto damaged samples: the induction heating generator and microwave heating machine. The induction heater used in this study has a capacity of $50 \mathrm{~kW}$ and a maximum frequency of $35 \mathrm{kHz}$. The damaged sample was placed under the induction heating coil and heated until $90^{\circ} \mathrm{C}$ (as shown in Figure 3). In addition, microwave heating treatment was conducted using a microwave oven with a maximum frequency of $2.45 \mathrm{MHz}$ and a power capacity of $700 \mathrm{~W}$. Damaged sample was subjected to electromagnetic waves for 50 seconds [20]. The surface temperature was recorded by an infrared camera (Figure 4).

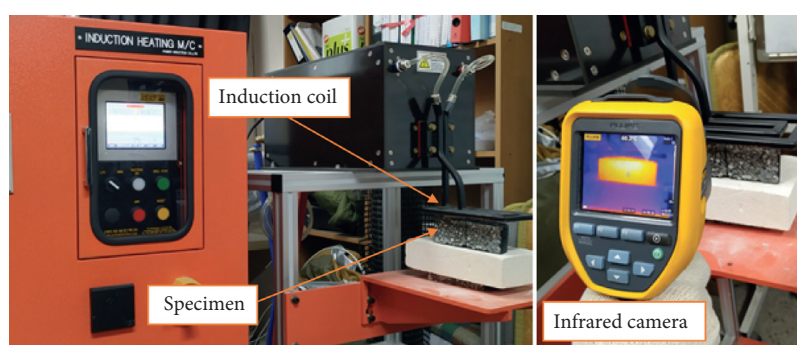

FIgURE 3: Induction healing test setup.

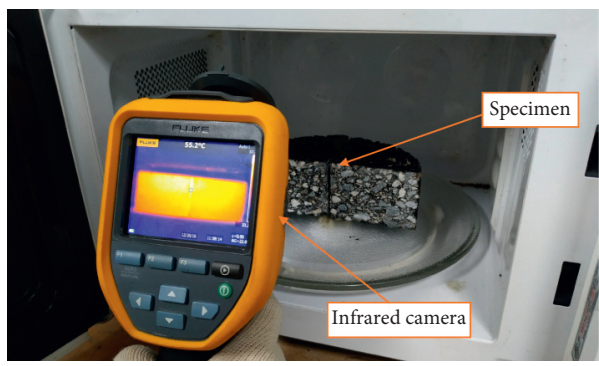

Figure 4: Microwave healing test setup.

After healing treatment, healed samples were allowed to rest approximately three hours to achieve stable room temperature. Rested and healed samples were again conditioned in a refrigerator for two hours and tested for the $\mathrm{TPB}$ test. This equates to one $\mathrm{DH}$ cycle. Based on preliminary research recommendations and the author's team experiment, the healing performance of the test samples was conducted until eight damage-healing cycles. The healing level of the asphalt mixture sample $S_{h}(\%)$ was calculated by

$$
S_{h}=\frac{F_{n}}{F_{0}} \times 100,
$$

where $F_{0}$ is the force of the initially tested sample (0 DH cycle) $(\mathrm{kN}) . F_{n}$ is the force of sample after the damagehealing process $\left(n^{\text {th }} \mathrm{DH}\right.$ cycle) $(\mathrm{kN})$.

\section{Results and Discussion}

3.1. Results of Surface Temperature after Healing Process. Figure 5 shows the relationship between surface temperature and several freeze-thaw cycles of unaged asphalt mixture composed of different types of additive agents. Overall, the temperature gradually decreased at every FT cycle. The results indicated that samples treated by microwave heating obtained a higher temperature than that of induction heating. This occurrence can be explained by the fact that any material exposed to electromagnetic radiation heats up, while magnetic induction only affects conductive objects (i.e., SWF) [24]. Among four types of additive agents and control samples, type 2 achieved the highest surface temperature in both microwave and induction heating. In addition, the trends of temperature variation between antistripping additives and rejuvenators were most similar. 


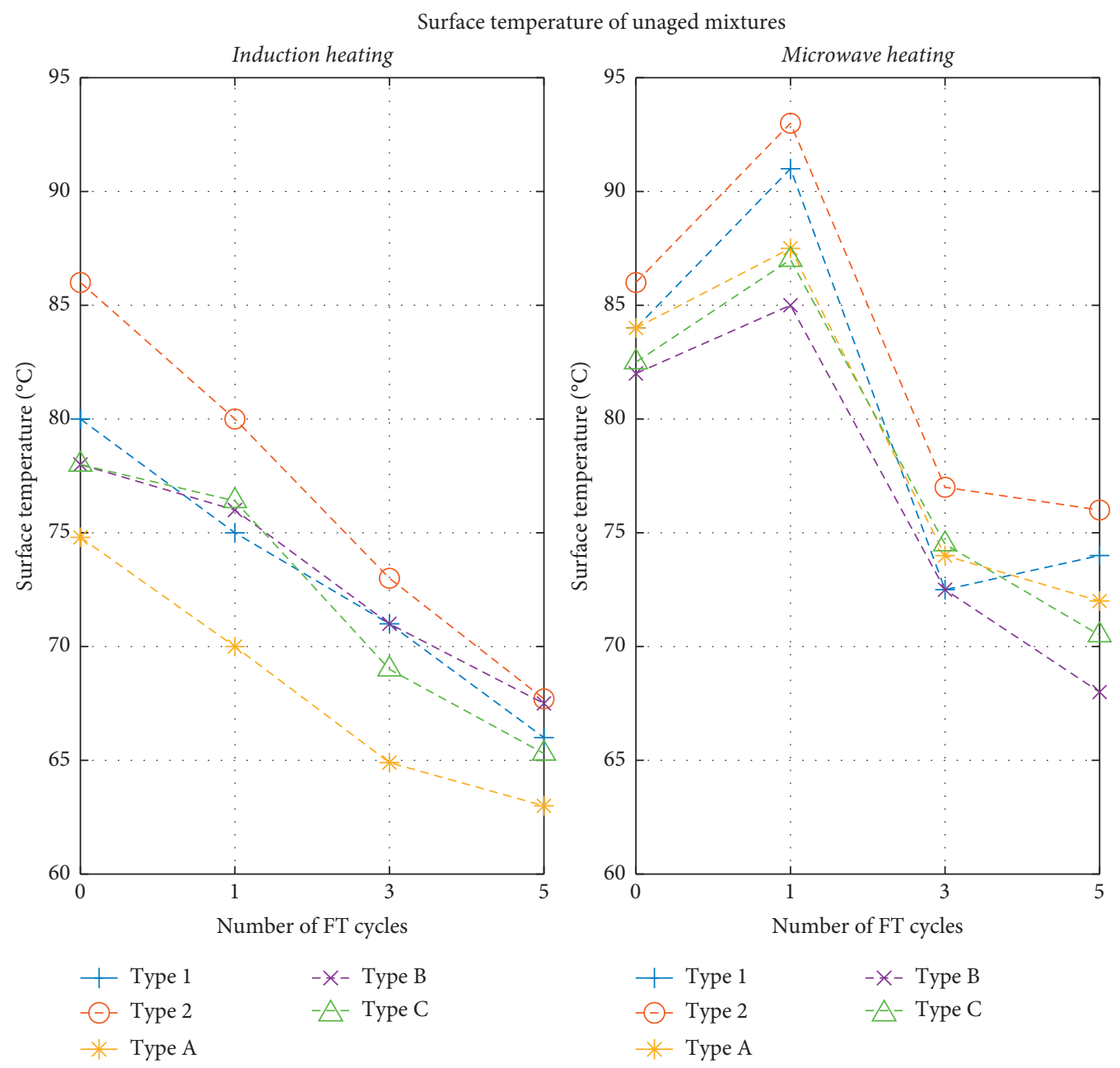

Figure 5: Surface temperature after healing.

By using microwave heating, the average surface temperature was increased after one FT cycle and decreased subsequently (see Figure 5 ). The type 2 mixture had the highest surface temperature of $93.5^{\circ} \mathrm{C}$, and type A presented the lowest temperature with $68.8^{\circ} \mathrm{C}$ (after five FT cycles). The increase in temperature at the early stages of FT cycle can be explained by the change of air void content. After one FT cycle, air void content within samples might have been sufficient to hold a substantial amount of water, which led to an increase in temperature. However, with successive FT cycles, the repetition of freezing and thawing may have caused much air void volume expansion [25], with bigger air gaps that led to the flow of moisture rather than retention [26]. Therefore, this may have caused a decrease in temperature due to the decrease in moisture content.

Under induction heating, the average surface temperature of samples gradually decreased with increasing FT cycles. The highest temperature was recorded in type 2 additive samples with $85^{\circ} \mathrm{C}$ (at $0 \mathrm{FT}$ cycles), and the lowest was type A with $63^{\circ} \mathrm{C}$ (after $5 \mathrm{FT}$ cycles). As mentioned before, when the number of FT cycles was increased, there would be higher air void content, thereby breaking the interconnecting bonds of the mixture (especially SWF). This phenomenon which led to heat transfer was interrupted. In addition, the water retained on the samples played a role as a thermal absorbing material, which lowers the temperature. Therefore, the temperature of test samples gradually reduced with an increasing FT cycle when using induction heating method. Temperature attainment after the healing process plays an important role during real-scale heating scenarios. With the results presented, it is conclusive that although it reached the margin of $80-90^{\circ} \mathrm{C}$, it is within boundaries of a regular asphalt pavement working temperature.

3.2. Results of Moisture Resistance. To better understand and express the indirect tensile strength of samples in this experiment, the tensile strength ratio (TSR) was computed. TSR is defined as the ratio of the tensile strength of both wetconditioned (i.e., 1, 3, and 5 FT cycles) and dry-conditioned samples (i.e., $0 \mathrm{FT}$ cycles). The tensile strength ratio can be calculated by following equation:

$$
\operatorname{TSR}_{k}^{i}=\frac{K_{i}}{K_{0}} \times 100,
$$

where $\operatorname{TSR}_{k}^{i}$ is tensile strength ratio of mixture with type " $K$ " additive agent at cycle " $i$," $K_{i}$ is the wet-conditioned tensile strength of mixture with " $K$ " additive agent at cycle " $i$," and 
$K_{0}$ is the dry-conditioned tensile strength of mixture with " $K$ " additive agent.

The results from Figure 6 show that additive could enhance moisture resistance of modified asphalt mixture. Particularly, mixtures containing antistripping archived the highest indirect tensile strength. With the dry condition, type A mixture showed the highest value of $1.89 \mathrm{MPa}$; however, the control mixture presented the lowest indirect tensile strength, which was $1.45 \mathrm{MPa}$. Overall, TSR of all asphalt mixtures decreased at every freeze-thaw cycle. The control mixture showed the lowest TSR values of 53\% and $19 \%$ after one and five FT cycles, respectively. The decrease in TSR could be caused by the presence of more air void content after succeeding in FT cycles. The antistripping additive samples had better results compared to samples modified with rejuvenators. This can be explained by the fact that antistripping additive increases adhesion between binder and aggregates, giving stronger tensile strength. Although lower in TSR percentage, the rejuvenator improved the moisture damage resistance of test samples by at most $85 \%$ over control. According to KS F 2398, the damage due to moisture is controlled by specific limits of the TSR. Under one cycle of freeze thaw, all of the antistripping samples meet the minimum criteria of TSR value of $80 \%$ [27].

Moreover, (4) was developed to analyze the effect of introducing additive agents unto the mixture at different freeze-thaw cycles:

$$
E_{k}^{i}=\frac{K_{i}-C_{i}}{C_{i}} \times 100,
$$

where $E_{k}^{i}$ is the tensile strength percentage improvement of mixture with type " $K$ " additive agent at cycle " $i$," $K_{i}$ is the tensile strength of mixture with " $K$ " additive agent at cycle " $i$," and $C_{i}$ is the tensile strength of control sample (without additive agent) at cycle " $i$."

Figure 7 illustrates the effect of adding additive agents. The bar graph shows that all mixtures with additive can improve tensile strength. The antistripping additive samples had significant improvement in tensile strength compared to rejuvenator additive samples. The improvement of the antistripping additive is visible in unconditioned state (0 FT cycles). Type B additive increased tensile strength by $32 \%$ over the control sample. On the other hand, rejuvenator additive samples imposed a slight increase of only $8 \%$ (at 0 FT cycles). The increase in tensile strength is caused by the characteristic of each additive. The antistripping additives can improve the adhesive between asphalt binders and aggregates, while rejuvenator can restore the mechanical properties of an aged binder [12].

\subsection{Results of Healing Performance}

3.3.1. Without Moisture Damage (0 FT Cycles). Table 4 shows the initial force of the moisture-damage series. Without moisture damage (i.e., 0 FT cycles), the mixtures containing additive agents were slightly improved initial force of asphalt mixture. The type B mixture was $7 \%$

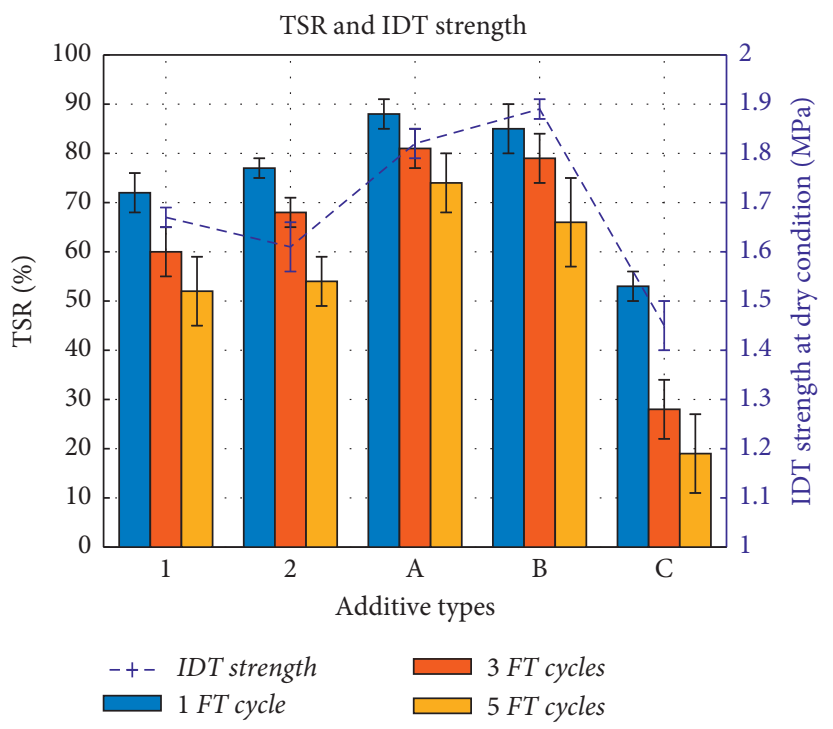

FIgURE 6: TSR and IDT strength of moisture-damaged mixtures.

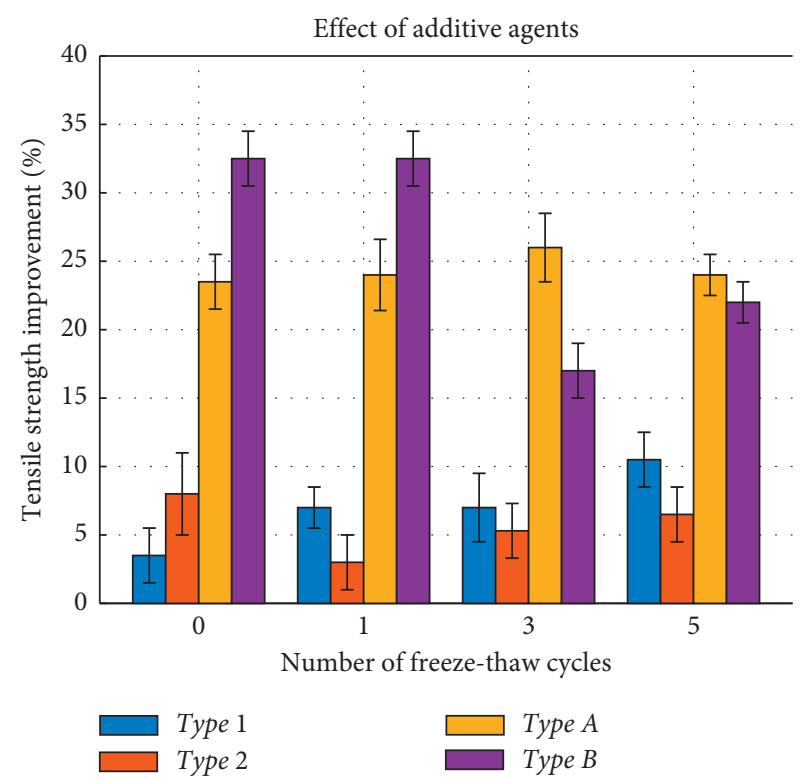

FIgURE 7: Tensile strength improvement.

higher than the control mixture. In addition, the healing performance of samples without moisture damage is shown in Figure 8. In general, the healing levels of all mixes decreased at every damage-healing cycle. The microwave heating method indicated a higher healing level than induction heating method. This outcome agrees well with the results previously discussed from attained surface temperature after the healing process. The higher surface temperature helps sufficient crack healing [18].

Under the microwave heating treatment, the effect of antistripping additives was less than that of rejuvenators. This can be seen at the fourth $\mathrm{DH}$ cycle, with rejuvenator type 2 mixture having a healing level of $76 \%$ compared to 
TABLE 4: The initial force of moisture damage asphalt mixtures $(\mathrm{kN})$.

\begin{tabular}{|c|c|c|c|c|c|}
\hline \multirow{2}{*}{ Freeze-thaw cycle } & \multicolumn{5}{|c|}{ Mixture types } \\
\hline & Type C & Type A & Type B & Type 1 & Type 2 \\
\hline 0 & $2.45 \pm 0.10$ & $2.56 \pm 0.13$ & $2.62 \pm 0.11$ & $2.53 \pm 0.11$ & $2.55 \pm 0.13$ \\
\hline 1 & $2.31 \pm 0.12$ & $2.52 \pm 0.14$ & $2.54 \pm 0.15$ & $2.43 \pm 0.13$ & $2.47 \pm 0.13$ \\
\hline 3 & $2.11 \pm 0.09$ & $2.45 \pm 0.09$ & $2.47 \pm 0.12$ & $2.39 \pm 0.12$ & $2.38 \pm 0.12$ \\
\hline 5 & $1.95 \pm 0.11$ & $2.21 \pm 0.12$ & $2.32 \pm 0.17$ & $2.33 \pm 0.16$ & $2.21 \pm 0.14$ \\
\hline
\end{tabular}

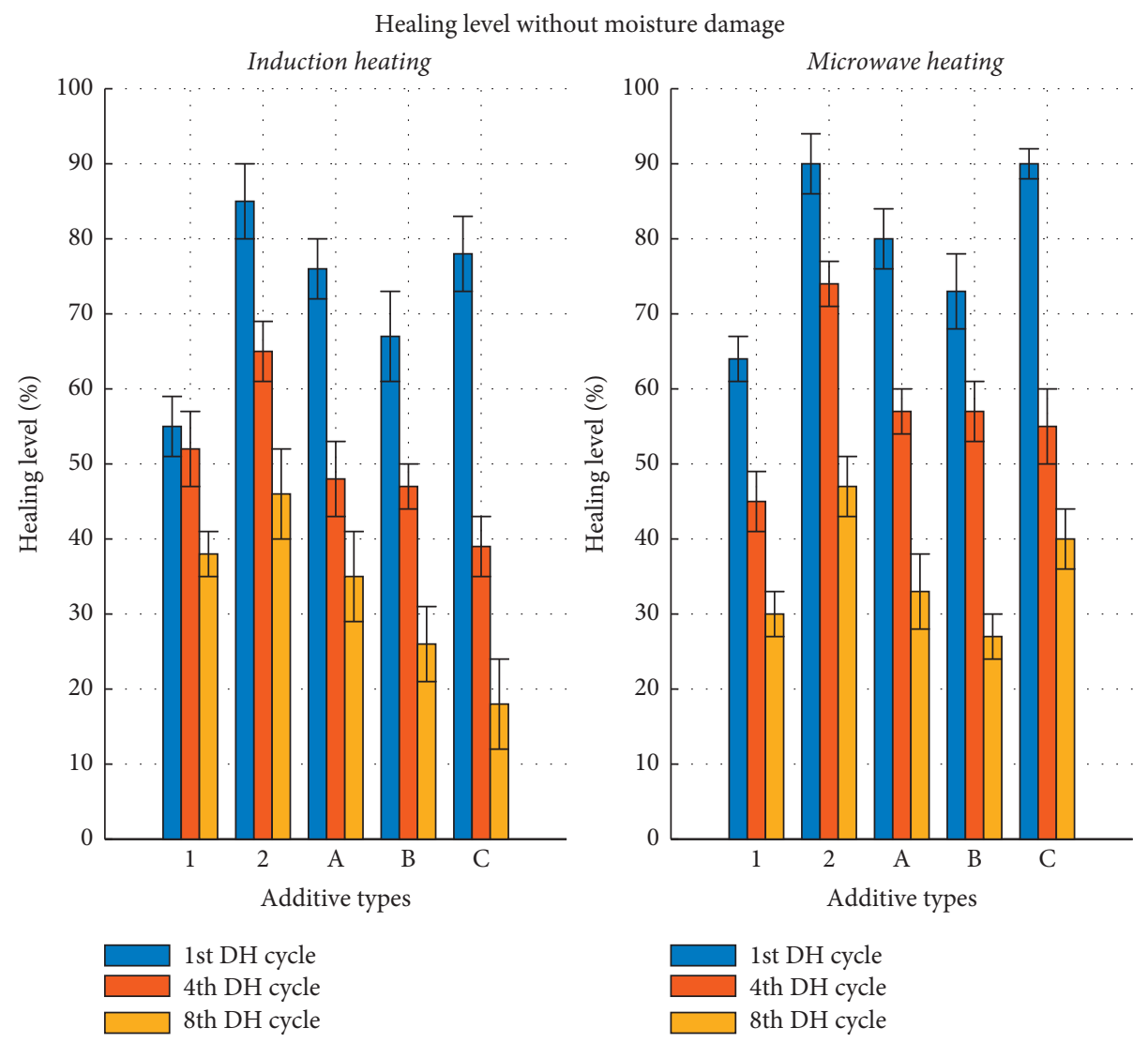

FIGURE 8: Healing level of unaged mixtures without moisture damage.

$55 \%$ for antistripping additive type B mixture. Type 2 mixture showed a promising healing performance with a level of $76 \%$ and $47 \%$ under 4 and 8 DH cycles, respectively. Additionally, the type 1 mixture had the lowest healing level of $43 \%$ and $29 \%$ corresponding to 4 and $8 \mathrm{DH}$ cycles. It can be explained due to the high viscosity of rejuvenator additive 1 , which causes slow and inefficient diffusion into the asphalt. In the early stages of DH cycles, the difference in the healing level of the control sample and additive agent sample was insignificant. Control samples also have healing capabilities effective until four DH cycles. Furthermore, from the fifth $\mathrm{DH}$ cycles, the effect of an additive agent, specifically rejuvenators, can have a significant impact on continuing the healing level above 50\%. Adding an appropriate rejuvenator (type 2 with lower viscosity) helps asphalt binder reduce its viscosity, which can explain a higher level of healing [28].
The healing result under induction heating is shown in Figure 8 . In early cycles of $\mathrm{DH}$, the mixtures without additive agents (control) and type 2 had a better healing level compared to other mixtures, obtaining $79 \%$ and $83 \%$, respectively. However, after 4 cycles, the healing performance of the control sample dropped significantly by $39 \%$. The results might be due to the repetition of damage-healing cycles, which lead to aging and oxidization of asphalt binder. As a result, it caused high viscosity that prevented the capillary flow of asphalt binders to repair cracks.

3.3.2. With Moisture Damage (1, 3, and 5 FT Cycles). The effect of additive agents was proved after one FT cycle (Table 4). The initial force of additive mixtures was approximately $10 \%$ higher than the control mixture. The healing performance of asphalt mixtures suffering from 


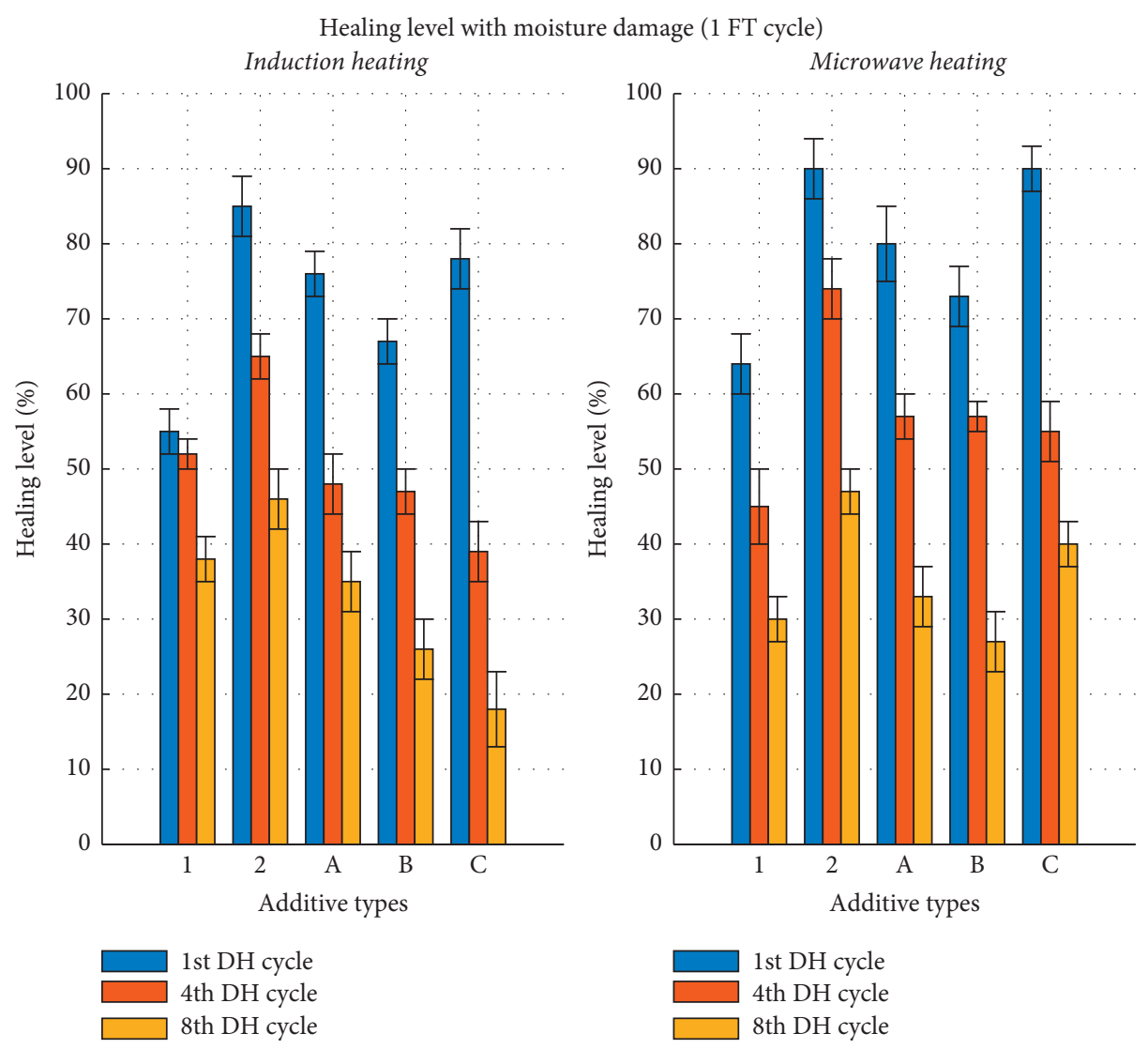

FIGURE 9: Healing level of unaged mixtures with moisture damage (1 FT cycle).

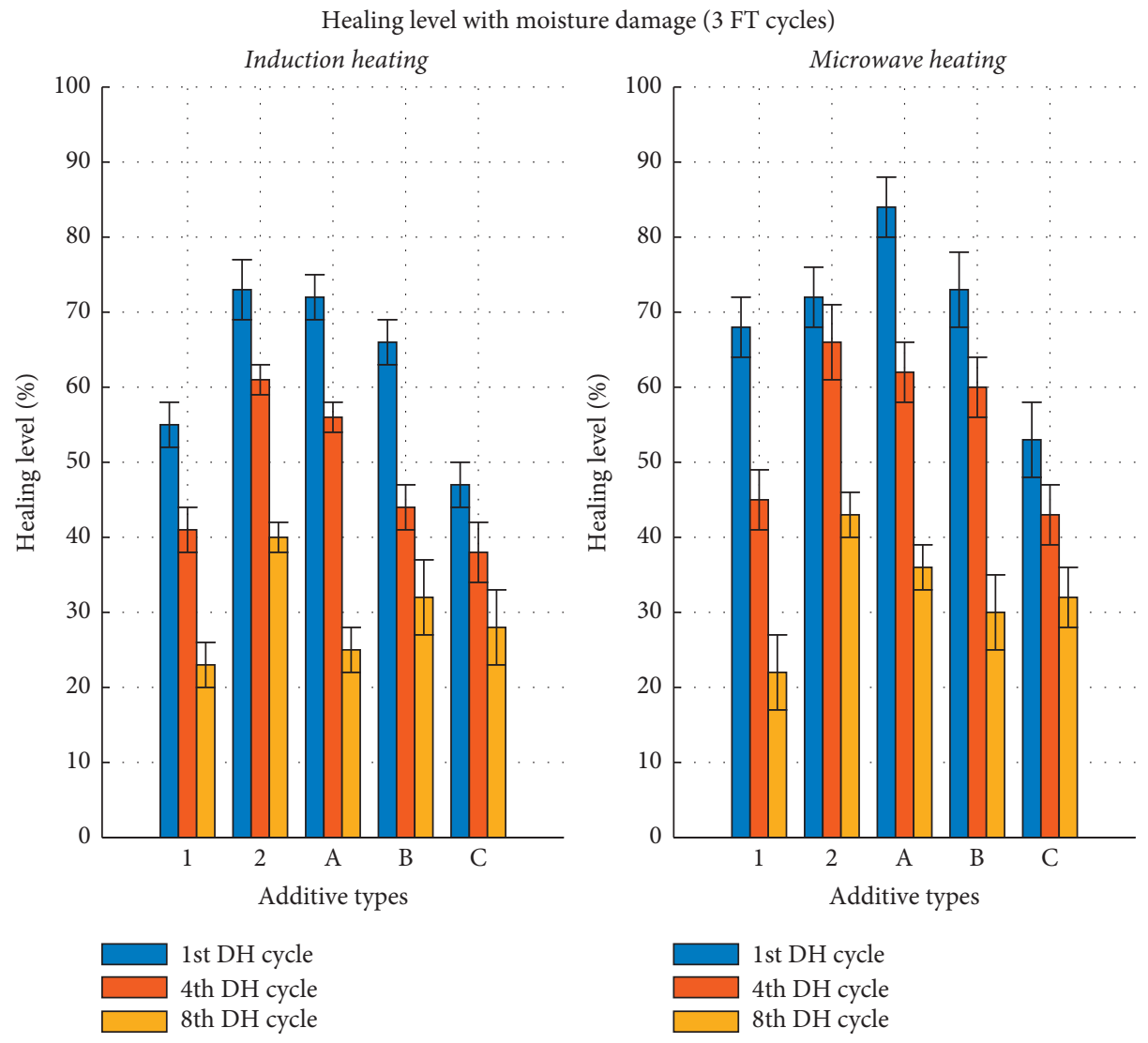

Figure 10: Healing level of unaged mixtures with moisture damage (3 FT cycles). 


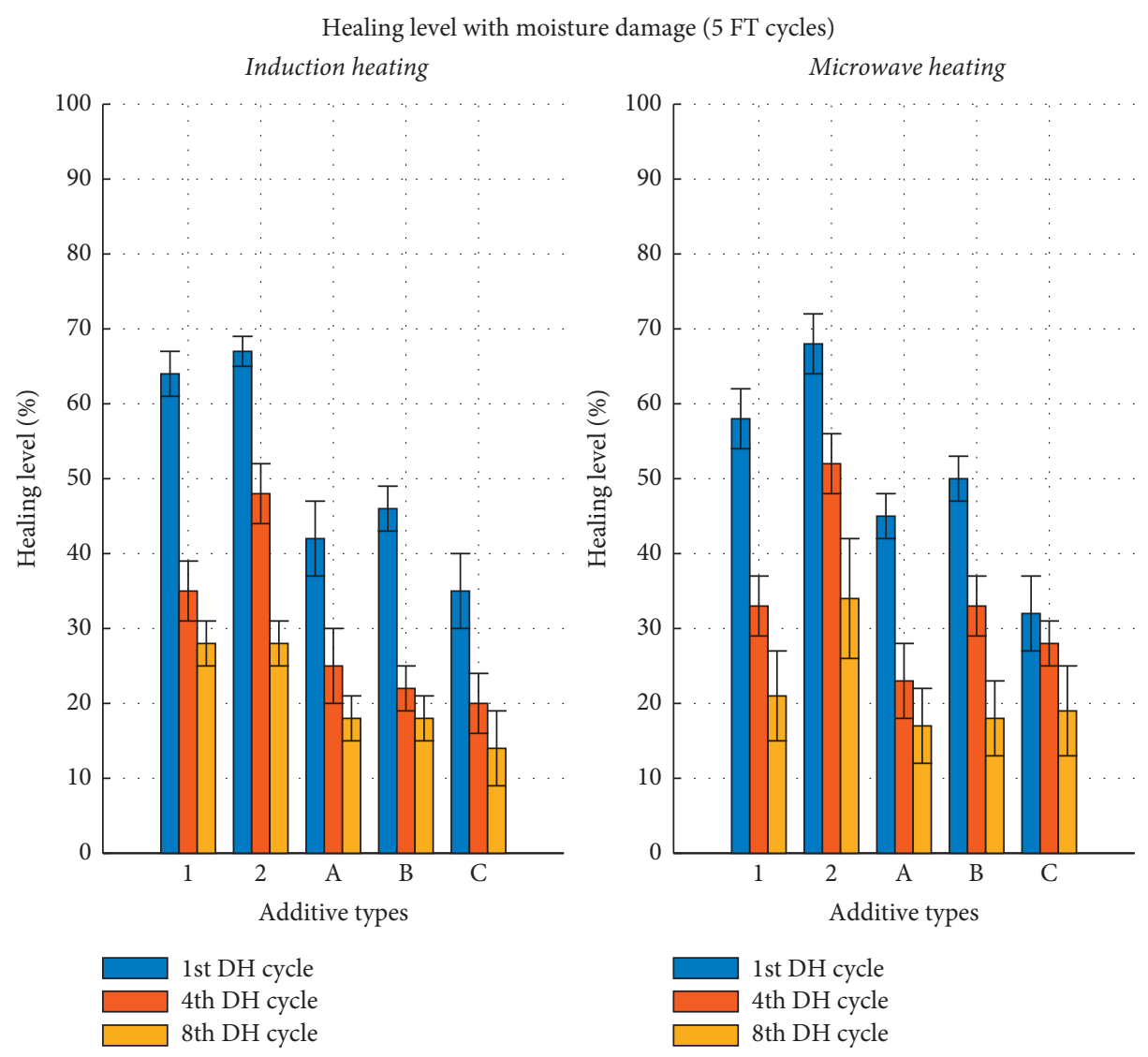

Figure 11: Healing level of unaged mixtures with moisture damage (5 FT cycles).

moisture damage is shown in Figures 9-11. Overall, the healing level decreased with increasing damage-healing cycle. Similarly, with the increasing FT cycles, the healing level decreased. This occurrence was observed for both microwave and induction heating method. Moreover, microwave heating showed a slight advantage in the healing level over induction heating for all FT cycles. Observing the figures, all mixtures with additive agents showed improvement in the healing level over control samples. However, during the late $\mathrm{DH}$ cycles, the gap on the healing level becomes less significant. This might be attributed to the limitation of the healing characteristics of a mixture with an additive agent during excessive $\mathrm{DH}$ cycles.

Figure 9 shows the corresponding healing level on every type of additive agent that underwent one FT cycle. It can be observed that type $\mathrm{A}$ antistripping additive obtained the highest healing level at $83 \%$ during one DH cycle. It is important to note that mixtures with type 2 rejuvenator additive had a better healing performance overall. At $8 \mathrm{DH}$ cycles, type 2 additive mixture showed an $8 \%$ higher healing level compared to type A mixture. By further observing Figures 10 and 11, type 2 additive samples show consistency in its healing level, obtaining $69 \%$ at $5 \mathrm{FT}$ cycles on $1 \mathrm{DH}$ cycle. Furthermore, it seems that antistripping additive can heal significantly only at the early cycles of FT. With Figure 11, the significant difference in using a rejuvenator additive over antistripping additive can be seen. This further proves the
TABLE 5: The initial force of aged damage asphalt mixtures $(\mathrm{kN})$.

\begin{tabular}{lccc}
\hline PAV damage & \multicolumn{3}{c}{ Mixture types } \\
& Type C & Type A & Type 2 \\
\hline $5 \mathrm{~h}$ & $2.36 \pm 0.13$ & $2.52 \pm 0.12$ & $2.57 \pm 0.14$ \\
$15 \mathrm{~h}$ & $2.26 \pm 0.15$ & $2.41 \pm 0.16$ & $2.43 \pm 0.13$ \\
$20 \mathrm{~h}$ & $2.01 \pm 0.15$ & $2.28 \pm 0.17$ & $2.25 \pm 0.16$ \\
\hline
\end{tabular}

advantageous effect of using rejuvenator for optimum selfhealing characteristics.

Similar trend results with microwave heating can be observed, with type 2 additive showing best healing performance and consistency on all mixtures. With moisture damage at $5 \mathrm{FT}$ cycles, type 2 rejuvenator additive samples showed $20 \%$ and $32 \%$ higher healing level compared to type $B$ antistripping additive samples and control samples, respectively. It is obvious that the healing performance of the mix with rejuvenators was better than that of the mixture with antistripping additives. The antistripping additives can protect the asphalt mixture from water intrusion and increase the adhesion of the aggregate to the asphalt binder. However, in terms of healing performance, rejuvenators with low viscosity can increase the flowability of an asphalt binder; hence, the binder can easily flow to repair microcracks. This observation also explains the high healing level of rejuvenator type 2 additive, which had the lowest viscosity value. The results highlight the important 


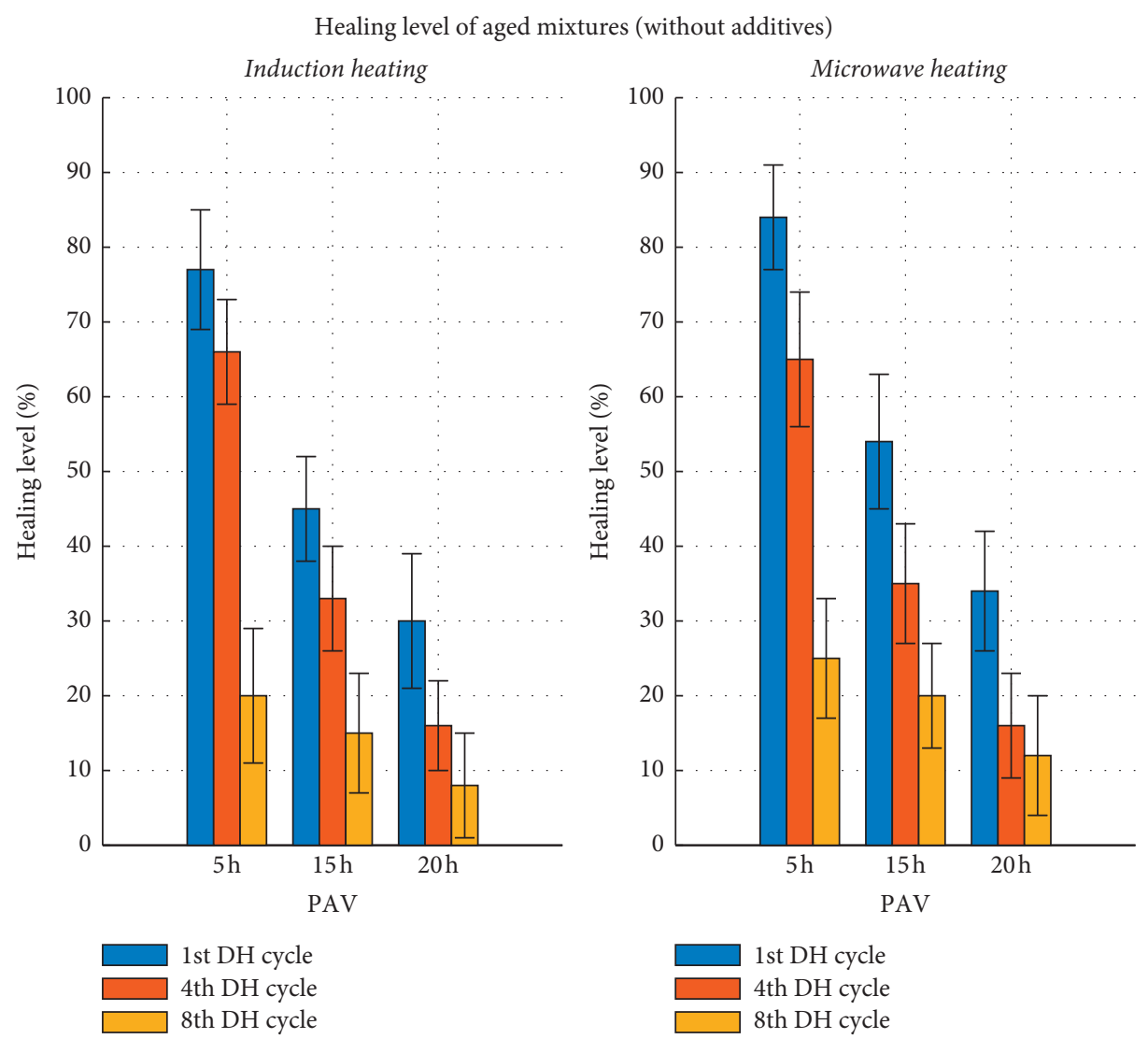

FIGURE 12: Healing level of aged mixtures without additive agents.

role of the viscosity of an additive agent in providing a selfhealing ability.

3.3.3. With Long-Term Aging. The containing of additive agents could enhance the initial force of aged asphalt mixtures (Table 5). Mixtures with additive agents gain a $10 \%$ higher compared to the control mixture. The healing level results of aged asphalt mixture without an additive agent are shown in Figure 12. Observing the general trend portrayed by the figure, aging shows a great influence on the healing performance of asphalt mixture. The longer aging exposure caused a smaller healing level. From both healing treatments, 5 hours aged mixture showed the highest healing result among other levels of aging. At the first DH cycle of PAV-5 hrs samples, the healing performance of induction and microwave was $78 \%$ and $83 \%$, respectively. During subsequent DH cycles until the fourth cycle, the healing level remained over $65 \%$. Meanwhile, the healing level of 15 hours and 20 hours significantly decreased by $50 \%$ in the first cycle of damage healing. It can be explained that longer aging exposure makes asphalt binder stiffer. The research result from Lin confirmed that penetration and ductility decrease with the increase of aging time. Particularly, penetration decreases significantly after PAV for 20 hours.
Figure 13 illustrates the healing performance of aged mixture modified with 2 additive agents (i.e., type 2 and type A) that undergone two different healing treatments. Overall, the healing level of aged mixtures is improved by using additive agents. Particularly, using rejuvenator additive type 2 showed good performance. At the initial stage of damage healing, all samples with rejuvenator additive kept their healing level over 70\%. The healing level of type 2 and type A showed a slight improvement compared to the control mixture; however, the improvement was significant only during late $\mathrm{DH}$ cycles on longer aging exposure. Different from rejuvenator additive, antistripping additive causes an increment of cohesion free energy [29], which is evident at the first stage of damage-healing.

The analysis of variance (ANOVA) with Tukey's HSD post hoc was used to evaluate the statistical significance of the change in healing performance with moisture-damaged and aging time (shown in Table 6). The result from ANOVA indicates that the healing performances of asphalt mixtures are significantly affected by moisture damage and long-term aging. However, there is no significant difference at $\alpha=0.05$ level between 3 FT cycles and 15 hours and also 5 FT cycles and 20 hours. In other words, a statistical correlation may be found between moisture damage and long-term aging within the scope and procedure of this experiment. 

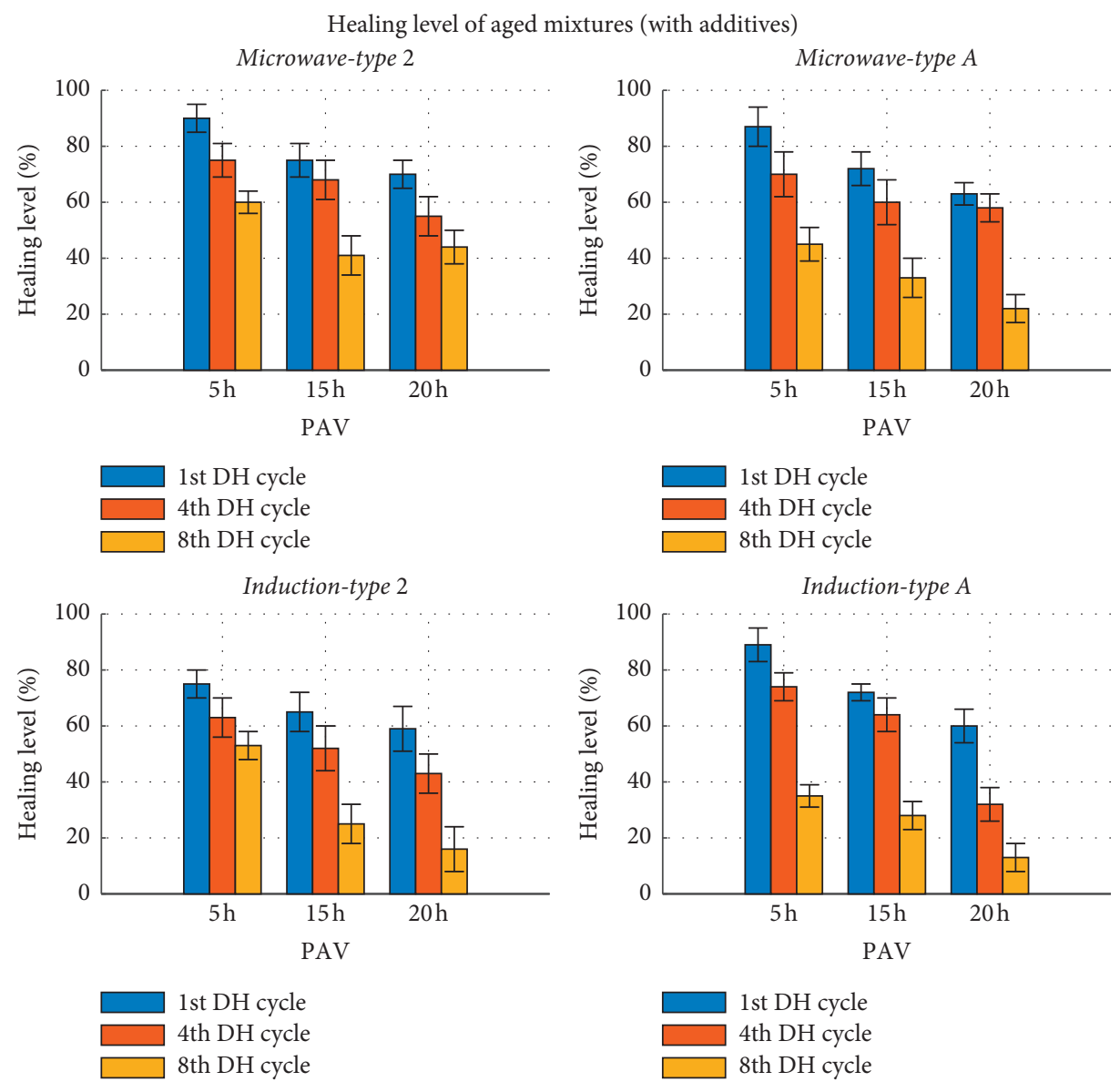

FIGURE 13: Healing level of aged mixtures modified with two additive agents.

TABle 6: Tukey's HSD post hoc summary result.

Types of damaged PAV 5 hours PAV 15 hours PAV 20 hours

\begin{tabular}{llll}
\hline 1 FT cycle & S & N & N \\
3 FT cycles & S & N & N \\
5 FT cycles & S & S & N
\end{tabular}

N: nonsignificant; S: significant.

\section{Conclusions}

In this study, the indirect tensile strength test and the threepoint bending test were conducted to investigate the effect of additive agents on the healing performance of hot mix asphalt under moisture and long-term aging damage. A series of test results showed that adding additive agents can improve the healing performance of asphalt mixture after being subjected to damage. The main research conclusions are presented as follows:

(i) Microwave heating method shows a better healing option than that of induction heating. The entire asphalt mixture heats up with electromagnetic radiation, while for magnetic induction, thermal energy disseminates only through conductive materials, that is, steel wool fibers.

(ii) Mixing asphalt binder with antistripping additive can obtain significant moisture resistance.
However, if healing performance is the primary goal of the mixture, a low viscosity rejuvenator additive is best.

(iii) Three to four damage-healing cycles on asphalt mixture, with or without moisture damage, are able to achieve prime healing performance.

(iv) The application of rejuvenators leads to the softening of the asphalt binder. This concept may enhance the healing performance of asphalt to some extent. Asphalt binders with rejuvenator may be softened faster under heating treatment, and the use of rejuvenator is expected to accelerate the crack healing process.

Following the statistic results of healing performance, there may have been a correlation between freeze-thaw cycles and long-term aging time in terms of healing performance, such as 3 freeze-thaw cycles with 15 hours of aging time and 5 freeze-thaw cycles with 20 hours of aging time. The mechanism correlation needs to be clarified in further studies.

\section{Data Availability}

The experimental data used to support the findings of this study will be made available from the corresponding author upon request. 


\section{Conflicts of Interest}

The authors declare that there are no conflicts of interest regarding the publication of this paper.

\section{Acknowledgments}

This research was supported by Basic Science Research Program through the National Research Foundation of Korea (NRF) funded by the Ministry of Education (no. NRF2017R1D1A1B03032594).

\section{References}

[1] G. D. Airey, "State of the art report on ageing test methods for bituminous pavement materials," International Journal of Pavement Engineering, vol. 4, no. 3, pp. 165-176, 2003.

[2] T. Ma, X.-m. Huang, E. Mahmoud, and E. Garibaldy, "Effect of moisture on the aging behavior of asphalt binder," International Journal of Minerals, Metallurgy, and Materials, vol. 18, no. 4, pp. 460-466, 2011.

[3] C. Miller, D. N. Little, A. Bhasin, N. Gardner, and B. Herbert, "Surface energy characteristics and impact of natural minerals on aggregate-bitumen bond strengths and asphalt mixture durability," Transportation Research Record: Journal of the Transportation Research Board, vol. 2267, no. 1, pp. 45-55, 2012.

[4] T. A. Rafiqul and A. Mohiuddin, "Evaluating the relationship between permeability and moisture damage of asphalt concrete pavements," Journal of Materials in Civil Engineering, vol. 27, no. 5, Article ID 4014172, 2015.

[5] D.-W. Park, W.-J. Seo, J. Kim, and H. V. Vo, "Evaluation of moisture susceptibility of asphalt mixture using liquid antistripping agents," Construction and Building Materials, vol. 144, pp. 399-405, 2017.

[6] J. Norambuena-Contreras and A. Garcia, "Self-healing of asphalt mixture by microwave and induction heating," $\mathrm{Ma}$ terials \& Design, vol. 106, pp. 404-414, 2016.

[7] H. Li, J. Yu, S. Wu et al., "Study on the gradient heating and healing behaviors of asphalt concrete induced by induction heating," Construction and Building Materials, vol. 208, pp. 638-645, 2019.

[8] v. B. Gerbert, "Self healing asphalt-extending the service life by induction heating of asphalt," in Proceedings of the 6th Eurasphalt and Eurobitume Congress, Prague, Czech Republic, June 2016.

[9] M. D. Elwardany, F. Yousefi Rad, C. Castorena, and Y. R. Kim, "Evaluation of asphalt mixture laboratory long-term ageing methods for performance testing and prediction," Road Materials and Pavement Design, vol. 18, no. 1, pp. 28-61, 2017.

[10] H. Bahia and D. Anderson, "The pressure aging vessel (PAV): a test to simulate reheological changes due to field aging," in Physical Properties of Asphalt Cement Binders, J. Hardin, Ed., pp. 67-88, West Conshohocken, PA, USA, 1994.

[11] D. Kuang, W. Liu, Y. Xiao, M. Wan, L. Yang, and H. Chen, "Study on the rejuvenating mechanism in aged asphalt binder with mono-component modified rejuvenators," Construction and Building Materials, vol. 223, pp. 986-993, 2019.

[12] A. F. Espinoza-Luque, I. L. Al-Qadi, and H. Ozer, "Optimizing rejuvenator content in asphalt concrete to enhance its durability," Construction and Building Materials, vol. 179, pp. 642-648, 2018.

[13] F. Wang, L. Zhang, B. Yan et al., "Diffusion mechanism of rejuvenator and its effects on the physical and rheological performance of aged asphalt binder," Materials, vol. 12, no. 24, 2019.
[14] S. Y. Teh and M. O. Hamzah, "Asphalt mixture workability and effects of long-term conditioning methods on moisture damage susceptibility and performance of warm mix asphalt," Construction and Building Materials, vol. 207, pp. 316-328, 2019.

[15] P. K. Das, R. Balieu, N. Kringos, and B. Birgisson, "On the oxidative ageing mechanism and its effect on asphalt mixtures morphology," Materials and Structures, vol. 48, no. 10, pp. 3113-3127, 2015.

[16] P. K. Das, H. Baaj, N. Kringos, and S. Tighe, "Coupling of oxidative ageing and moisture damage in asphalt mixtures," Road Materials and Pavement Design, vol. 16, no. 1, pp. 265-279, 2015.

[17] M. R. B. McGennis, R. M. Anderson, T. W. Kennedy, and M. Solaimanian, Background of Superpave Asphalt Mixture Design and Analysis, National Asphalt Training Center Demonstration Project 101, Lexington, KY, USA, 1995.

[18] B. H. Dinh, D.-W. Park, and T. H. M. Le, "Effect of rejuvenators on the crack healing performance of recycled asphalt pavement by induction heating," Construction and Building Materials, vol. 164, pp. 246-254, 2018.

[19] H. Li, J. Yu, Q. Liu et al., "Induction heating and healing behaviors of asphalt concretes doped with different conductive additives," Advances in Materials Science and Engineering, vol. 2019, Article ID 2190627, 10 pages, 2019.

[20] T. M. Phan, D.-W. Park, and T. H. M. Le, "Crack healing performance of hot mix asphalt containing steel slag by microwaves heating," Construction and Building Materials, vol. 180, pp. 503-511, 2018.

[21] Á. García, "Self-healing of open cracks in asphalt mastic," Fuel, vol. 93, pp. 264-272, 2012.

[22] ASTM D2872-12, Standard Test Method for Effect of Heat and Air on a Moving Film of Asphalt (Rolling Thin-Film Oven Test), American Society for Testing Materials, West Conshohocken, PA, USA, 2012.

[23] AASHTO T 283, Standard Method of Test for Resistance of Compacted Asphalt Mixtures to Moisture-Induced Damage, American Association of State Highway and Transportation Officials, Washington, DC, USA, 2014.

[24] J. Norambuena-Contreras, R. Serpell, G. Valdés Vidal, A. González, and E. Schlangen, "Effect of fibres addition on the physical and mechanical properties of asphalt mixtures with crack-healing purposes by microwave radiation," Construction and Building Materials, vol. 127, pp. 369-382, 2016.

[25] P. Pan, S. Wu, X. Hu, P. Wang, and Q. Liu, "Effect of freezingthawing and ageing on thermal characteristics and mechanical properties of conductive asphalt concrete," Construction and Building Materials, vol. 140, pp. 239-247, 2017.

[26] X. Chen and B. Huang, "Evaluation of moisture damage in hot mix asphalt using simple performance and superpave indirect tensile tests," Construction and Building Materials, vol. 22, no. 9, pp. 1950-1962, 2008.

[27] AASHTO T 283, Testing Method for Resistance of Compacted Asphalt Mixtures to Moisture Induced Damage, American Association of State Highway and Transportation Officials, Washington, DC, USA, 2012.

[28] T. Ma, X. Huang, Y. Zhao, and Y. Zhang, "Evaluation of the diffusion and distribution of the rejuvenator for hot asphalt recycling," Construction and Building Materials, vol. 98, pp. 530-536, 2015.

[29] G. H. Hamedi and S. A. Tahami, "The effect of using antistripping additives on moisture damage of hot mix asphalt," International Journal of Adhesion and Adhesives, vol. 81, pp. 90-97, 2018. 